\title{
Recombinant Human Growth Hormone Acts on Intermediate-Sized Follicles and Rescues Growing Follicles From Atresia
}

\author{
KIYoshi OZAWA, Hideki MIZUNUMA, Hitoshi OZAWA*, AND Yoshito IBUKI \\ Department of Obstetrics and Gynecology, Gunma University School of Medicine, Maebashi 371, and \\ *Laboratory of Molecular and Cellular Morphology, Department of Cell Biology, Institute for Molecular \\ and Cellular Regulation, Gunma University, Maebashi 371, Japan
}

\begin{abstract}
In order to clarify the role of GH on ovarian function, recombinant human GH (rhGH) was administered to adult spontaneous dwarf rats (SDR) for 14 days. The SDR were sacrificed on the day of estrus and the effects of rhGH on ovarian weight, follicular population and the viability estimated by 5bromodeoxyuridine (BrdU) incorporation, were studied. RhGH administration caused a significant gain in body weight of the SDR, and the ovarian weight of the GH-injected SDR showed a significant increase in comparison with saline injected SDR. The total population of follicles was significantly greater in the $\mathrm{GH}$-treated group than in the control, and the difference was attributed to the increase in the number of large follicles more than $500 \mu \mathrm{m}$. Total uptake of BrdU into granulosa cells was significantly higher in $\mathrm{GH}$-treated rats than in the control, and, in particular, the intermediate-sized follicles $(300-500 \mu \mathrm{m})$ of the GH-treated rats showed signs of high incorporation of BrdU. These results suggest that hGH acts on intermediate follicles, stimulates their viability and increases the number of growing follicles.
\end{abstract}

Key words: GH, Ovary, 5-Bromodeoxyuridine (BrdU), Spontaneous dwarf rat

(Endocrine Journal 43: 87-92, 1996)

THERE is increasing evidence that GH plays an important role in follicular growth and pubertal development in mammals [1,2]. It is reported that suppression of endogenous GH release in female rats reduces ovarian $\mathrm{LH}$ receptor content and delays the onset of puberty [3], while GH administration to congenital GH-deficient rats stimulates progesterone secretion and restores the time of the onset of puberty [4]. On the other hand, in vitro studies with FSH-stimulated granulosa cell cultures demonstrated that the action of GH on ovarian function is direct and augments LH receptor formation $[5,6]$. In addition to its effects on granulosa

Received: August 1, 1995

Accepted: October 24, 1995

Correspondence to: Dr. Hideki MIZUNUMA, Department of Obstetrics and Gynecology, Gunma University School of Medicine, 3-39-15 Showamachi, Maebashi, Gunma 371, Japan cell differentiation, $\mathrm{GH}$ treatment also stimulates folliculogenesis. Administration of recombinant bovine $\mathrm{GH}$ increases the number of small follicles in cows [7], and treatment with GH augments the folliculogenic response of the human ovary to gonadotropin stimulation $[8,9]$. These indicate the importance of GH in the regulation of ovarian function, but the use of $\mathrm{GH}$ as a cogonadotropin still remains controversial [10], because the role of $\mathrm{GH}$ in the reproductive process is permissive. But interest in the potential use of $\mathrm{GH}$ as an adjunctive agent in the context of ovulation induction has been growing. It is therefore necessary to elucidate the in vivo role of $\mathrm{GH}$ in follicular development, and in particular to morphologically clarify at what stage of follicular development GH evokes its action. In order to elucidate this, we studied the effect of recombinant human $\mathrm{GH}$ (rhGH) on follicular development in the congenital GH deficient rats. 


\section{Materials and Methods}

\section{Animals}

Spontaneous dwarf rats (SDR) produced and supplied by Roussel Morishita Co., Ltd were housed in a temperature-controlled vivarium (at $20 \pm 2{ }^{\circ} \mathrm{C}$ illuminated from $0700 \mathrm{~h}$ to $1700 \mathrm{~h}$ ). Food and water were available ad libitum. Both male and female SDR were reproductively competent, although the litter size was smaller than that of normal parents. A vaginal smear test was carried out before and during the experiments, and it was confirmed that the female SDR had 4 day vaginal cycles.

\section{Experimental procedure}

Twenty-one-week-old SDR were divided into two groups, 6 to each group. Subcutaneous injections of recombinant human GH (rhGH) $(200 \mathrm{mIU} /$ $\mathrm{mL}$ ) (Saizen, Ares-Serono Laboratories) were started at $0800 \mathrm{~h}$ on the first day and were continued for 14 days in the experimental group. The same amount of saline was administered to the control. Blood sampling was carried out from the cervical vein under light ether anesthesia after 14 days of $\mathrm{GH}$ administration (at $0800 \mathrm{~h}$ on the estrus day) for radioimmunoassay (RIA) of LH, FSH and inhibin. Blood samples were centrifuged and serum was stored at $-20^{\circ} \mathrm{C}$ until assayed. Immediately after blood sampling, the ovaries were removed, cleaned of fat, weighed and then fixed in Bouin's solution. One hour before blood sampling, the rats were intraperitoneally injected with 5-bromodeoxyuridine (BrdU) (5 mg/body), a thymidine analog, which is incorporated into DNA in the S-phase of the cell cycle.

\section{Histological analysis}

The ovaries fixed in Bouin's solution were embedded in paraplast after dehydration with an ascending ethanol series. Eight-micron-thick serial sections were cut from each ovary, alternate sections were stained with hematoxylin and eosin (HE), and the remainder of the sections was used for the immunohistochemistry to estimate the BrdU incorporation. Every section stained with $\mathrm{HE}$ was scanned in a color image analyzer SP-500 (Olym- pus), and follicles more than $100 \mu \mathrm{m}$ in diameter (including theca) showing ovum nuclei were measured. Classification of follicular size into 3 groups (100-300 $\mu \mathrm{m}, 300-500 \mu \mathrm{m}$ and more than $500 \mu \mathrm{m}$ ) was done arbitrarily. BrdU incorporation was visualized in paraplast-embedded material using a monoclonal anti-BrdU antibody to BrdU (Cell proliferation kit RUN.20 Amersham) followed by an indirect peroxidase staining procedure. The BrdU incorporation rate was assessed as the number of BrdU positive nuclei on the representative section (maximal section including oocyte) of each follicle.

\section{RIA}

Serum concentrations of FSH and LH were determined in duplicate by a double antibody RIA, with materials supplied by NIDDK. Rat FSH and LH RP-1 were used as a reference standard and the concentration was expressed in $\mu \mathrm{g} / \mathrm{ml}$. Serum concentrations of inhibin were also determined in duplicate by RIA as previously described [11], and expressed in $\mathrm{ng} / \mathrm{ml}$.

\section{Statistics}

Comparison of the means for the 2 groups was analyzed by non-parametrical analysis by using the Mann-Whitney method. Results were considered statistically significant if $P$ was $<0.05$.

\section{Results}

The effects of $\mathrm{GH}$ on body weight, ovarian weight and serum hormone levels are shown in Table 1. Significant increases in body weight and ovarian weight were observed in GH-treated rats. The body weight was increased to about 3.4 fold of the control, and the ovarian weight was increased to about 1.5 fold of the control. There were no significant differences between the GHtreated group and the control group in serum FSH concentrations, but serum inhibin levels of $\mathrm{GH}$ treated rats increased significantly $(P<0.05)$ compared to the control group. Serum LH was not detected.

Figure 1 demonstrates the effects of GH on follicular development. The total population of follicles was significantly greater in the $\mathrm{GH}$-treated group than in the control, and the difference was attrib- 
Table 1. Effect of GH treatment on body weight, ovarian weight and serm hormone levels of SDR

\begin{tabular}{lccccc}
\hline & $\mathrm{N}$ & $\begin{array}{c}\text { Gain in body } \\
\text { weight }(\mathrm{g})\end{array}$ & $\begin{array}{c}\text { Ovarian } \\
\text { weight }(\mathrm{mg})\end{array}$ & $\begin{array}{c}\text { Serum FSH } \\
(\mathrm{ng} / \mathrm{ml})\end{array}$ & $\begin{array}{c}\text { Serum inhibin } \\
(\mathrm{ng} / \mathrm{ml})\end{array}$ \\
\hline Control & 6 & $6.3 \pm 4.2$ & $24.6 \pm 4.1$ & $107 \pm 27$ & $2.1 \pm 0.3$ \\
GH treated & 6 & $21.3 \pm 3.0^{* *}$ & $36.5 \pm 2.4^{* *}$ & $118 \pm 57$ & $2.8 \pm 0.4^{*}$ \\
\hline
\end{tabular}

Results are mean $\pm \mathrm{SD}$. ${ }^{*} P<0.05$ and ${ }^{* *} P<0.01$ vs. control.

Follicle size (diameter: $\mu \mathrm{m}$ )

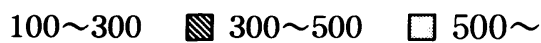

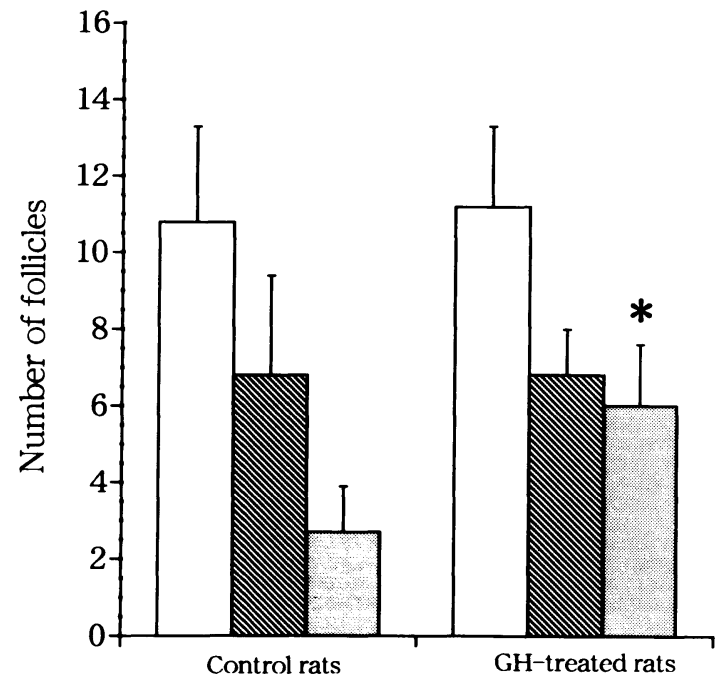

Fig. 1. Effect of GH on follicular population in SDR rats. Eight micron-thick serial sections were cut from each ovary. Every section stained with $\mathrm{HE}$ was scanned in a color image analyzer SP-500 (Olympus), and follicles more than $100 \mu \mathrm{m}$ in diameter (including theca) with ovum nuclei were measured. Classification of follicular size into 3 groups (100-300 $\mu \mathrm{m}, 300-500 \mu \mathrm{m}$ and more than 500 $\mu \mathrm{m})$ was determined arbitrarily. The total number of follicles was significantly greater in GH-treated rats than in the control. The difference was attributed to the increase in the population of large follicles. ${ }^{*} P<0.01 \mathrm{vs}$. control.

uted to the increase in the number of follicles larger than $500 \mu \mathrm{m}$. Figures 2 and 3 show a comparison of BrdU uptake in the control and the GH-treated SDR. In both groups, BrdU uptake was active in the small to large follicles. Total uptake of BrdU into granulosa cells was significantly higher in $\mathrm{GH}$ treated rats than in the control. Particularly the intermediate-sized follicles (300-500 $\mu \mathrm{m})$ of the GHtreated rats showed high incorporation of BrdU.

\section{Discussion}

The spontaneous dwarf rats were isolated from a closed colony of Sprague-Dawley rats in 1977 [12]. These rats demonstrated isolated GH deficiency caused by the point mutation in the GH gene, producing an abnormal splicing of $\mathrm{GH}$ mRNA [13]. The body weight of SDR is only 30$40 \%$ that of normal SD rats at the same age, but increases in response to the administration of normal pituitary extracts [12]. No immunohistochemically positive cells were found when using the antiserum to ovine $\mathrm{GH}$, but other anterior pituitary hormone producing cells, such as PRL, $\mathrm{ACTH}, \mathrm{TSH}, \mathrm{LH}$, and FSH cells were observed [14, 15]. Both male and female SDR were reproductively competent and are considered to be an excellent experimental model for the study of isolated GH deficiency.

The present study demonstrates that rhGH administration is able to significantly increase ovarian weight, the total number of follicles and immunoreactive inhibin secretion in SDR. These findings are in agreement with previous studies performed on hypophysectomized rats [16] and infertile humans receiving $\mathrm{GH}$ and urinary gonadotropins for in vitro fertilization $[8,9,17]$. Although recent studies suggest the importance of the role of $\mathrm{GH}$ and possibly insulin-like growth factor(IGF)-1 in regulating granulosa cell function $[2,5,6,18,19]$, it has not been fully elucidated to what extent the action of GH or IGF-1 is prerequisite. Menashe et al. [16] reported two women with Laron type dwarfism in whom spontaneous pregnancies occurred and Dor et al. [21] demonstrated that it is possible to induce ovulation by human menopausal gonadotropins administration in women with Laron type dwarf- 


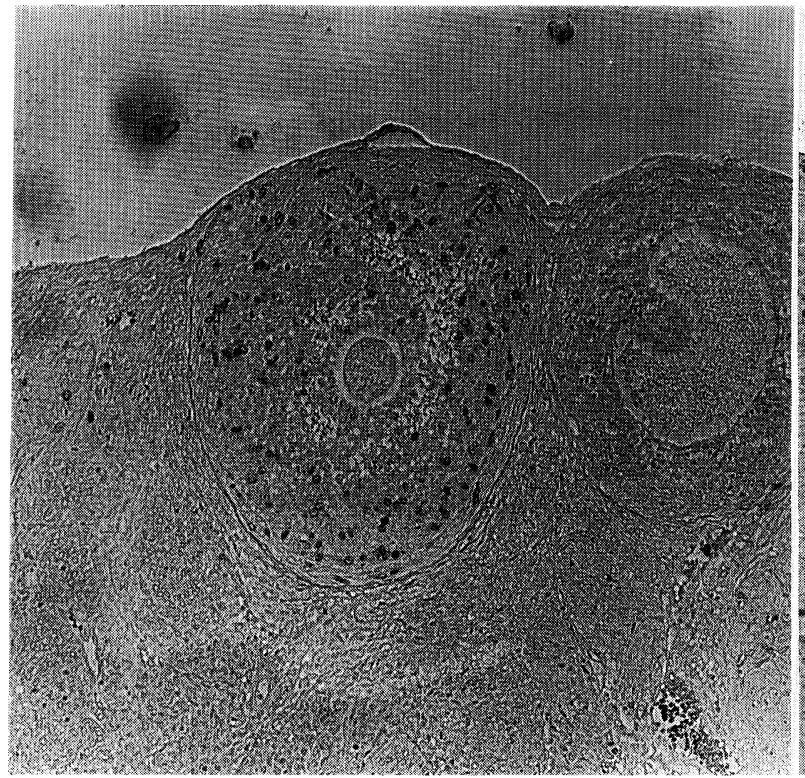

Control

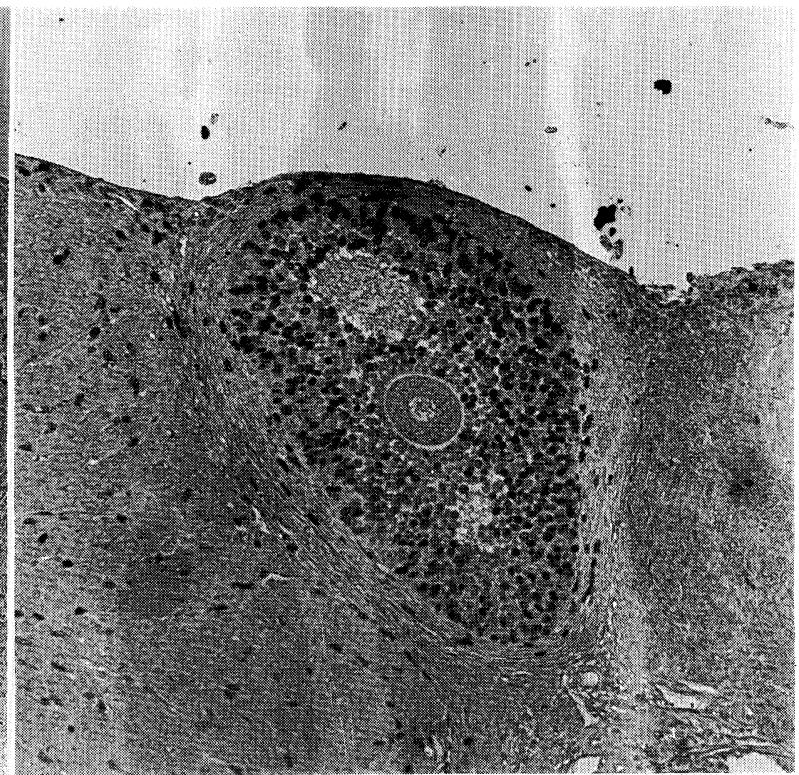

GH treated

Fig. 2. Photomicrograms of histological sections of the intermediate-sized follicles from control and GH-treated rats injected with BrdU $1 \mathrm{~h}$ before sacrifice. Uptake of BrdU into granulosa cells was higher in GH-treated rats than in the control. Particularly the intermediate-sized follicles $(300-500 \mu \mathrm{m})$ of the GH-treated rats showed signs of high incorporation of BrdU.

Follicle size (diameter: $\mu \mathrm{m}$ )
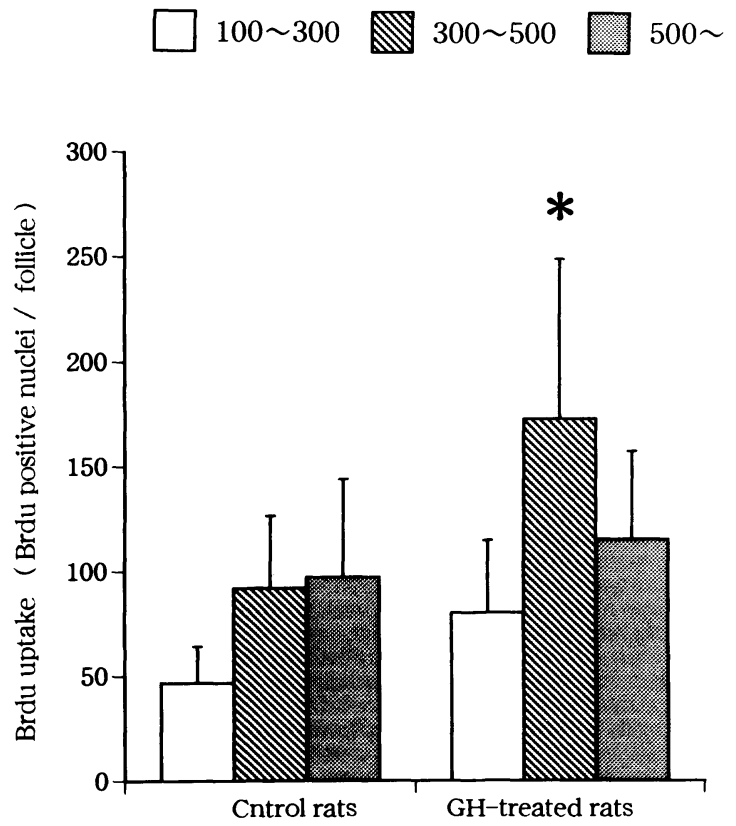

Fig. 3. Comparison of BrdU uptake into follicles of control and GH treated SDR rats. Total uptake of BrdU into granulosa cells was significantly higher in GH-treated rats than in the control. The difference was attributed to the uptake into the intermediate-sized follicles. ${ }^{*} P<0.01 \mathrm{vs}$. control. ism, suggesting that GH or IGF-1 is not essential but plays a modulatory role in ovarian follicular development. The present findings show the presence of spontaneous follicular development from the small- to large-sized follicles in SDR.

Recombinant human GH was thought to be nonlactogenic [22], but recent studies have shown that $\mathrm{GH}$ reacts with lactogenic receptors and $\mathrm{rhGH}$ increases the number of terminal end buds and alveolar buds in hypophysectomized rats [23]. It is therefore likely that the stimulatory effects of rhGH on follicular development are mediated through lactogenic receptors. In this study, we demonstrated that SDR treated with rhGH had been showing signs of a normal estrus cycle during rhGH administration, suggesting that the lactogenic effects of rhGH were less manifested. In addition, that $\mathrm{GH}$ exerts its effects on follicular development through somatogenic receptors would be supported by following observations: 1) PRL inhibits ovarian weight gain by decreasing the number of follicles in PMS-treated immature rats in a dose related manner [24], whereas a daily dose of $1600 \mathrm{mIU}$ of rhGH significantly increased the weight of the ovaries in PMS-treated immature rats 
(our unpublished data), and 2) GH stimulates follicular growth and maturation but PRL does not have such effects in perfused rabbit ovary $[25,26]$. Although expression of GH receptor mRNA has been demonstrated in the rat ovary [27], further studies on characterization of the biochemical properties of GH receptors and analysis of interaction between $\mathrm{GH}$ and its receptors are required.

As shown in Fig. 2, a significant increase in the number of follicles in the GH treated rats was due to the increase in the number of large follicles but there was no significant difference in the number of small and intermediate follicles. The increase in the number of follicles leads to increased serum inhibin levels, but the serum FSH of rhGH treated rats was unchanged, suggesting that the inhibitory effect of inhibin on FSH secretion was offset by $\mathrm{GH}$ treatment by unknown mechanisms. The effect of GH on the follicle population showed remarkable contrast to that of activin $\mathrm{A}$, a dimer of the $\beta$-subunit of inhibin, which increased not only large follicles but also small and intermediate follicles [28]. Stahmokinetic analysis of granulosa cells indicates that the large follicles in adult rats on the day of estrus are destined to become atretic during that night or the morning of the next day [29]. Furthermore, it has been shown that these large follicles are seemingly healthy but are not capable of ovulating in response to exogenously administered hCG [30]. If this is the case, the large follicles on the day of the estrus are remnant follicles which were stimulated by endogenous FSH but were not ovulated. The low BrdU incorporation into the large follicles in this study would support the hypothesis that the large follicles have lost viability.

Although small follicles which have a single or double layer of granulosa cells showed signs of high BrdU incorporation, there were no significant differences between the $\mathrm{GH}$-treated group and the control in BrdU incorporation, suggesting that the effects of $\mathrm{GH}$ are less evident in these small follicles at a very early stage of development. High BrdU incorporation was also observed in the intermediate follicles, and in particular the BrdU incorporation into intermediate follicles was significantly higher in GH-treated rats than in the control group, suggesting that $\mathrm{GH}$ exerts its action on the intermediate follicles. These intermediate follicles are thought to be driven from the new cohort and ovulate in the subsequent cycle [29], so that viability of the intermediate follicles is of particular importance in defining the number of growing follicles in the subsequent cycle. Our present study was quite compatible with recent findings by Eisenhauser et al. [31], which demonstrated that GH prevents follicular apoptosis and acts as an ovarian survival factor.

From these observations, it is concluded that $\mathrm{GH}$ is not mandatory for follicular development, but augments follicular growth in the presence of FSH. $\mathrm{GH}$ acts on intermediate follicles and increases their viability to protect from atresia and increases the number of growing follicles.

\section{Acknowledgments}

We are grateful to Roussel Morishita Co., Ltd for providing spontaneous dwarf rats, and to AresSerono Laboratories for providing recombinant human growth hormone. We also thank Dr. Kazumasa Kurosumi for valuable discussion on the study.

\section{References}

1. Ojeda SR, Jameson HE (1984) Developmental patterns of plasma and pituitary growth hormone (GH) in the female rat. Endocrinol 100: 881-889.

2. Adashi EY, Resnick C E, D'ercole AJ, Svoboda ME, Van Wyk JJ (1985) Insulin-like growth factors as intraovarian regulators of granulosa cell growth and function. Endcr Rev 6: 400-420.

3. Ramaley JA, Phares CK (1980) Delay of puberty onset in females due to suppression of growth hormone. Endocrinol 106: 1989-1993.
4. Andrzuj B (1964) Histological of the anterior hypophysis, thyroid and gonads of two types of dwarf mice. Anatomy Rec 149: 225-229.

5. Hsueh AJW, Adashi EY, Jones PBC, Welsh Jr TH (1984) Hormonal regulation of the differentiation of cultured ovarian granulosa cells. Endocr Rev 5: 76-127.

6. Jia X, Kalmijin J, Hsueh AJW (1986) Growth hormone enhances follicle-stimulating hormoneinduced differentiation of cultured rat granulosa 
cells. Endocrinol 118: 1401-1409.

7. Gong JG, Bramley TA, Webb R (1991) The effect of recombinant bovine somatotropin on ovarian function in heifers: Follicular populations and peripheral hormones. Biol Reprod 45: 941-949.

8. Homberg MB, West C, Torresani T, Jacob HS (1990) Cotreatment with human growth hormone and gonadotropins for induction of ovulation: A controlled clinical trial. Fertil Steril 53: 254-260.

9. Blumenfeld Z, Lunenfeld B (1989) The potentiating effect of growth hormone on follicle stimulation with human menopausal gonadotropin in a panhypopituitary patient. Fertil Steril 52: 328-331.

10. Katz E, Ricciarelli E, Adashi EY (1993) The potential relevance of growth hormone to female reproductive physiology and pathophysiology. Fertil Steril 59: 8-34.

11. Hasegawa Y, Miyamoto K, Igarasi M (1989) Changes in serum concentrations of immunoreactive inhibin during the oestrous cycle of the rat. $J$ Endocrinol 121: 91-100.

12. Okuma S, Kawashima S (1980) Spontaneous dwarf rat. Exp Animal 29: 301-304 (In Japanese).

13. Takeuchi T, Suzuki H, Sakurai S, Nogami H, Okuma S, Ishikawa H (1990) Molecular mechanism of growth hormone $(\mathrm{GH})$ deficiency in the spontaneous dwarf rat: Detection of abnormal splicing of $\mathrm{GH}$ messenger ribonucletic acid by the polymerase chain reaction. Endocrinol 126: 31-38.

14. Okuma S (1980) Study of growth hormone in spontaneous dwarf rat. Folia Endocrinol 60: 1005.

15. Nogami H, Suzuki K, Matsui K, Okuma S, Ishikawa H (1989) Electron-microscopic study on the anterior pituitary gland of spontaneous dwarf rats. Cell and Tissue Research 258: 477-482.

16. Jorgensen KD, Nowak J (1989) Interaction of human growth hormone and gonadotrophins on the function of rat ovaries. Pharmacology $\mathcal{E}$ Toxicology 65: 278-281.

17. Owen EJ, Shoham Z, Mason BA (1991) Cotreatment with growth hormone, after pituitary suppression, for ovarian stimulation in in vitro fertilization: A randomized, double-blind, placebo-control trial. Fertil Steril 56: 1104-1110.

18. Hsu C, Hammond JM (1987) Concomitant effects of growth hormone on section of insulin-like growth factor I and progesterone by cultured porcine granulosa cells. Endocrinol 121: 1343-1348.

19. Schams D, Koll R, Li CH (1988) Insulin-like growth factor-I stimulates oxytocin and progesterone production by bovine granulosa cells in culture. $J$ Endocrinol 116: 97-100.
20. Menashe Y, Sach J, Mashiach S (1991) Spontaneous pregnancies in two women with Laron-type dwarfism: are growth hormone and circulating insulin-like growth factor mandatory for induction of ovulation? Human Reprod 6: 670-671.

21. Dor J, Ben-shlomo I, Lunenfeld B, Pariente Cl, Levran D, Karasikl A, Seppala M, Mashiach S (1992) Insulin-like growth factor-I (IGF-I) may not be essential for ovarian follicular development: Evidence from IGF-I deficiency. J Clin Endocrinol Metab 74: 539-542.

22. Jorgensen KD, Nowak J (1989) Interaction of human growth hormone and gonadotrophins on the function of rat ovaries. Pharmacology $\mathcal{E}$ Toxicology 65: 278-281.

23. Feldman M, Ruan W, Cunningham BC, Wells JA, Kleinberg DL (1993) Evidence that the growth hormone receptor mediates differentiation and development of the mammary gland. Endocrinol 133: 1602-1608.

24. Larsen JL, Bhanu A, Odell WD (1990) Prolactin inhibition of pregnant mare's serum stimulated follicle development in the rat ovary. Endocr Res 16: 449459.

25. Yoshimura Y, Maruyama K, Shiraki M, Kawakami S, Fukushima M, Nakamura Y (1990) Prolactin inhibits plasminogen activator in the preovulatory follicles. Endocrinol 126: 631-616.

26. Yosimura $Y$, Iwasita $M$, Nakamura $Y$, Adachi T, Koyama N, Takeda Y (1993) Effects of growth hormone on follicle growth, oocyte maturation, and ovarian steroidogenesis. Fertil Steril 59: 917-923.

27. Tiong TS, Herington AC (1991) Tissue distribution, characterization, and regulation of messenger ribonucleic acid for growth hormone receptor and serum binding protein in the rat. Endocrinol 129: 1628-1634.

28. Doi M, Igarashi M, Hasegawa $Y$, Eto $Y$, Shiba $H$, Miura T, Ibuki Y (1991) In vivo action of activin-A on pituitary-gonadal system. Endocrinol 130: 139144.

29. Hirshfield AN (1984) Stathmokinetic analysis of granulosa cell proliferation in antral follicles of cyclic rats. Biol Reprod 31: 52-58.

30. Hirshfield AN (1986) Patterns of $\left[{ }^{3} \mathrm{H}\right]$ thymidine incorporation differ in immature rats and mature, cycling rats. Biol Reprod 34: 229-235.

31. Eisenhauser KM, Chun S, Billing H, Hsueh AJW (1995) Growth hormone suppression of apoptosis in preovulatory follicles and partial neutralization by insulin-like growth factor binding protein. Biol Reprod 53: 13-20. 